\title{
A Platform for Technical Consultation of Service Providers in Rapid Prototyping
}

\author{
Claus Aumund-Kopp, Frank Ellebrecht, Holger Fricke, Holm Gottschalch \\ and Christian Panse \\ University of Bremen, Institute of Industrial Technology and Applied Work Science, \\ Hochschulring 20, D-28359 Bremen, Germany. \\ Email: \{ak, el, got,pan\}@biba.uni-bremen.de
}

\begin{abstract}
An e-business platform for communication and interaction with customers and partners was designed and built. On this platform customers from anywhere can communicate anytime about rapid prototyping services. Partners and suppliers anywhere can be subcontracted or can be integrated in a network for specific services. Networks can be developed, or at least, chains can be unfolded. Technical advice for customers can be performed on the platform and mobile with a virtual show-case on a laptop at the customer's site. A "knowledge cube" allows to allocate and connect information in three dimensions. - The new style of working in networks and interacting online with customers and partners presupposes some training and qualification as well as acceptance and motivation for the evolving characteristics of "networking" and "collaborating", which are described and defined. A comparison of activity patterns and communicative behaviour "today and tomorrow" is performed. The evolution of a new style of interacting and communicating in networks ("networking") implies an adequate understanding of and a new concept for organisation and enterprise as well as concepts for new forms of cooperation / collaboration.
\end{abstract}

Key words: $\quad$ E-Business platform, Networking \& collaborating; Training \& qualification

\section{THE $A G E P R O$ ONLINE PLATFORM}

Customer requirements in product development and especially in rapid prototyping and rapid tooling have changed; they demand longer and complete process chains in even shorter lead times. To meet these demands of 
accelerated product development in interaction with customers and cooperating partners small and medium sized enterprises (SMEs) should extend their activities on the internet and develop internal e-business structures.

\subsection{Description of the Platform}

The agepro project built an online communication platform for SMEs in model and tool production which is closely oriented towards special needs of very fast Rapid Prototyping services. End users in five SMEs participated in software development during a cyclic-iterative process. In several workshops user expectations, needs and requirements were explored; programme specifications were defined; test versions of the platform were exposed to future users and their critique and suggestions were integrated in the next versions.

The platform is embedded into the company's website and opened by a browser interface. The agepro online platform assists rapid prototyping service providers in communicating and interacting with customers on the one hand and partners on the other, it allows and supports :

- customer acquisition and technical advice in a "virtual showcase"

- online requests of customers and specification and calculation of orders

- order status information by basic tracking functionalities,

- documentation for the company's internal use, collecting information on both successful and problematic orders and on customers

- allocation of important information with a three dimensional core competencies-employee-customer matrix called "knowledge cube".

The platform accelerates and improves the overall flow and storage of information, increases transparency of order control and production planning, harmonises transactions, improves training, and creates knowledge bases. However, no replacement of personal (face to face) customer contact is intended. In this respect, the platform will be no more than an additional communication channel.

\subsection{Platform Use Scenarios}

The communication platform will be used in different ways (Figure 1):

- a visitor looks into the virtual showcase in order to get information on a specific geometry of a model building process,

- a (new) customer demands information on the status of his order, especially on time limits,

- a technical advisor of the service provider visits customers at their site and exhibits masterpieces and demonstrates new processes in the virtual showcase 
- internal staff has access to all kinds of information on the platform and may contribute or complete new information to the "virtual showcase", to the "lessons learnt" and to the "knowledge cube".

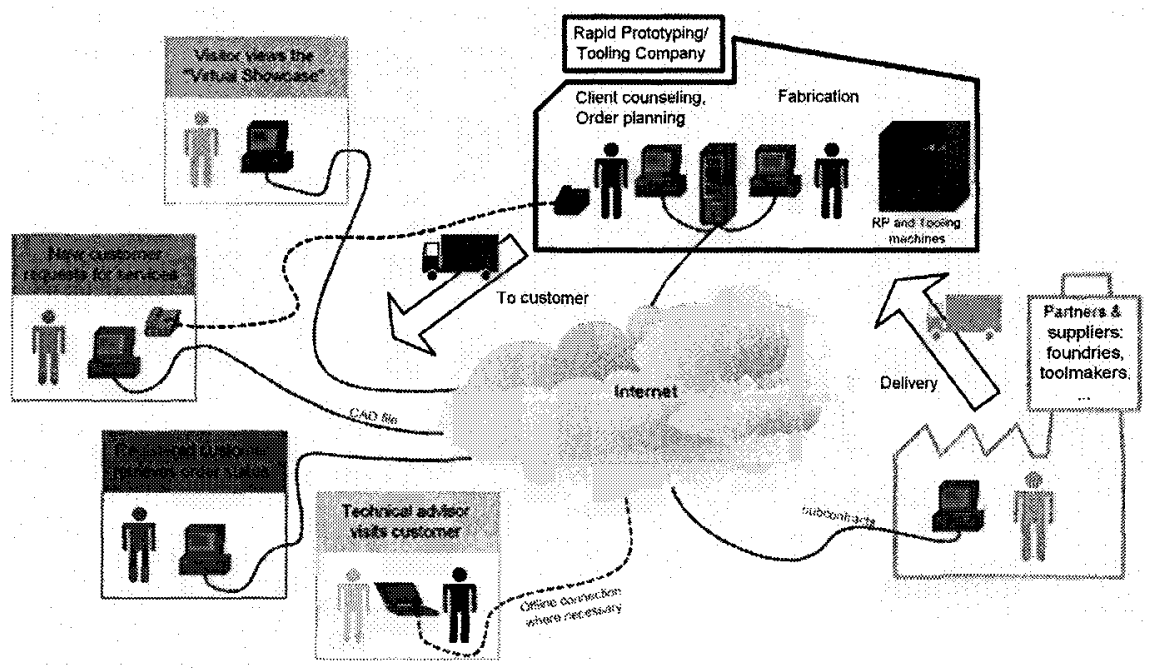

Figure 1. Different platform use situations

Figure 2 shows in a formal way which platform functionalities can be accessed by which type of user.

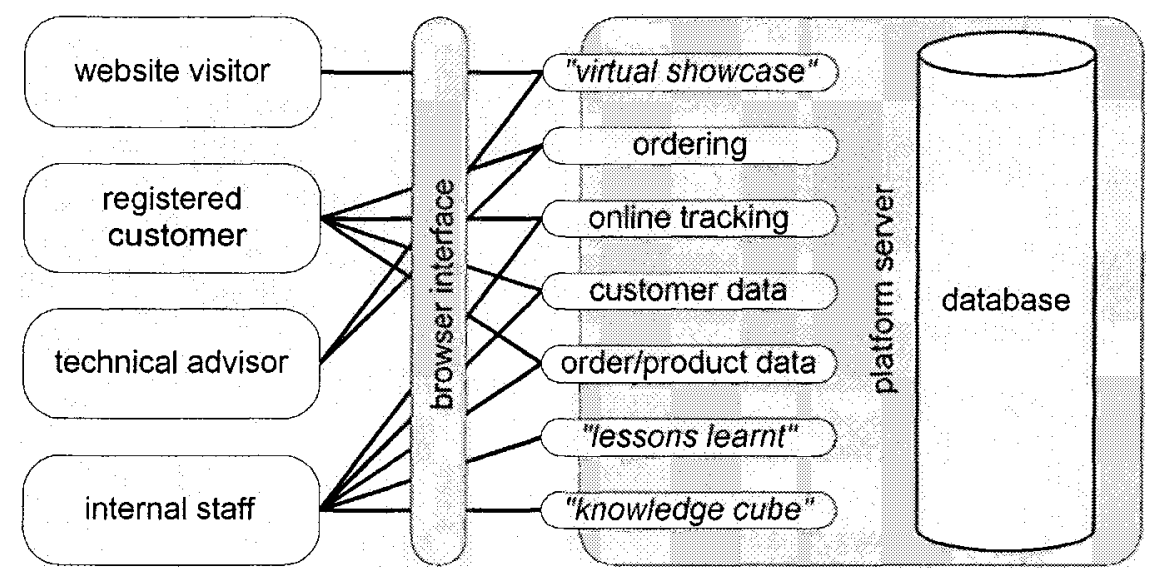

Figure 2. Dedicated functionalities for different types of users (Source: AUMUND-KOPP et al. 2003, p. 189) 


\section{THE "VIRTUAL SHOWCASE"}

When we visited model building companies we were always led to showcases containing masterpieces, sample parts and failures; new potentialities and challenges of rapid prototyping techniques are demonstrated proudly in this way and the limits of new techniques are discussed with these examples at hand. Technical consultation with a customer on special geometric features is easier and more precise with the object at hands or at least its 3 dimensional representation.

In order to support these demonstrations a "virtual showcase" was developed and integrated as a module into the agepro platform. On the one hand, it allows customers (from any place if there is www access) to have a close look at an exhibition of products or geometry similar to that they want to build and, on the other hand, it allows the company to exhibit its competencies - masterpieces and innovative RP-technologies - in the web.

Figure 3 shows the 2nd level of our example of the "virtual showcase". The user gets an overview of RP-methods and services and can choose an item for further information. The 3 rd level - not shown here - offers more detailed information on the chosen process, e.g. stereolithography and its potentialities, or the user may select a specific sample part generated by stereolithography (Figure 4). The parts itself are on 4th level.

\section{agepro \\ BIBA}

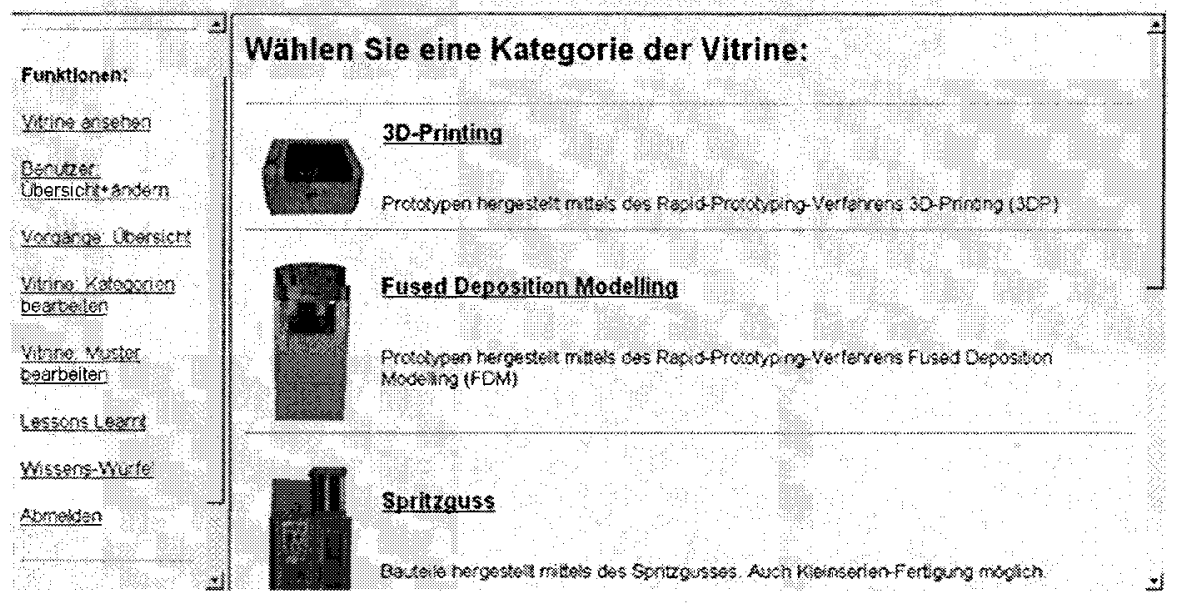

Figure3. Example of the "virtual showcase", menu and 2nd level, showing different rapid prototyping methods 
Technical advisors and customers can discuss and analyse specific features of the sample part and get visual support in the virtual showcase. They may check on specific geometry or applicable coatings, looking at a corresponding example on the screen. Both may sit in different places locally but look at the same part in the "virtual showcase" and communicate via telephone or they may have a look at the advisor's laptop and sit together in the customer's office. From the customer's point of view it is easy to inform himself before getting into contact with a company to clarify details. From the advisor's point of view this avoids carrying some dozens of physical models to a customer.

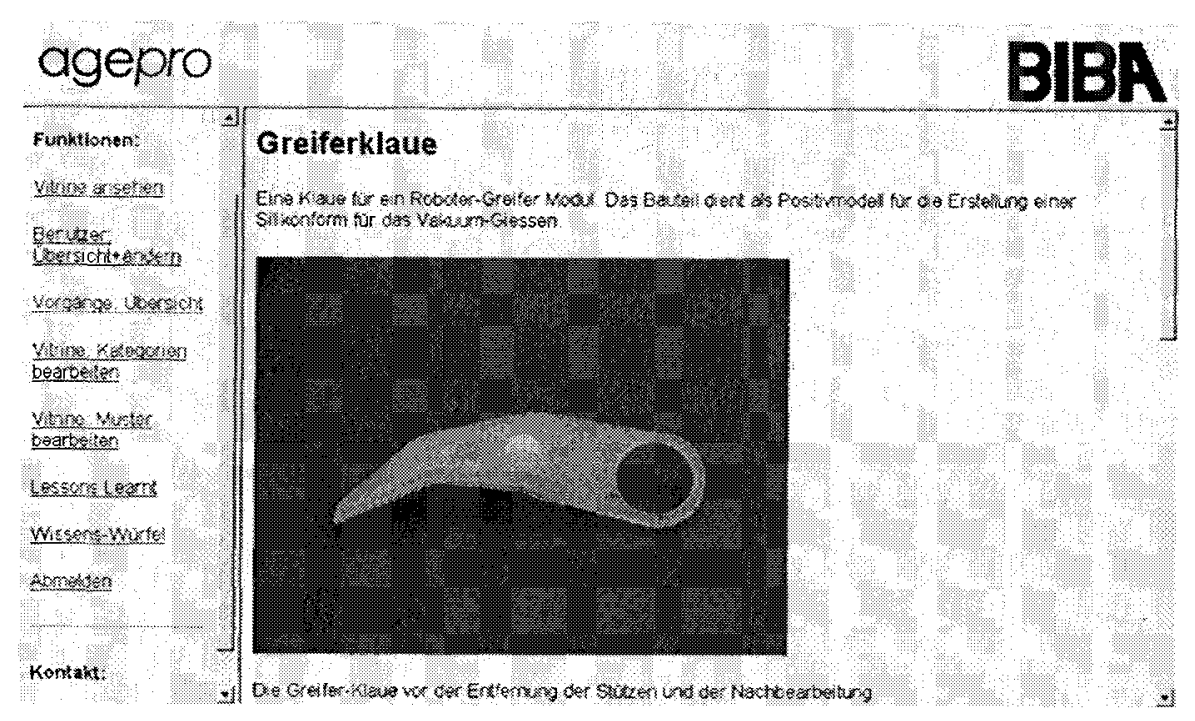

Figure -4. Example of the "virtual showcase", menu and 4th level, showing a sample part made by stereolithography

Another promising application of the "virtual showcase" is internal training. The "virtual showcase" can easily be filled with content. You can put masterpieces or failed attempts in it - the so called "lessons learned". Company staff can be trained by these examples; they can learn from mistakes and failures and may learn something about the limits (precision, tolerances) of an innovative RP-technology (however, failures should not be exposed to the public in the web). This relates a feature of the virtual showcase to the "knowledge cube", it supports a company's knowledge management : you can best learn from your mistakes.

Of course this tool must be kept up-to-date, everybody should contribute new masterpieces and lessons learned or observations on the limits of a new RP-technology. 


\section{THE "KNOWLEDGE CUBE"}

\subsection{Representation and Allocation of Knowledge by Defining Relations between List Elements}

The "Knowledge Cube" is a component of the agepro communication platform, dedicated to store and display in a weighted manner relationships between customers, employees, and topics/core competencies of a company. The weights of relationships are intended to be helpful in analysing strengths and weaknesses of the company, in finding optimisation potentials, and planning organisational change.

Customers, employees and topics are held in three lists of a database. For each two elements from different lists it can be defined interactively (via a semi-graphical user interface) whether the relationship between them is strong, medium, weak or inexistent. In this way, information can be allocated in three dimensions, connected and related to each other, and the strength of connections can be expressed.

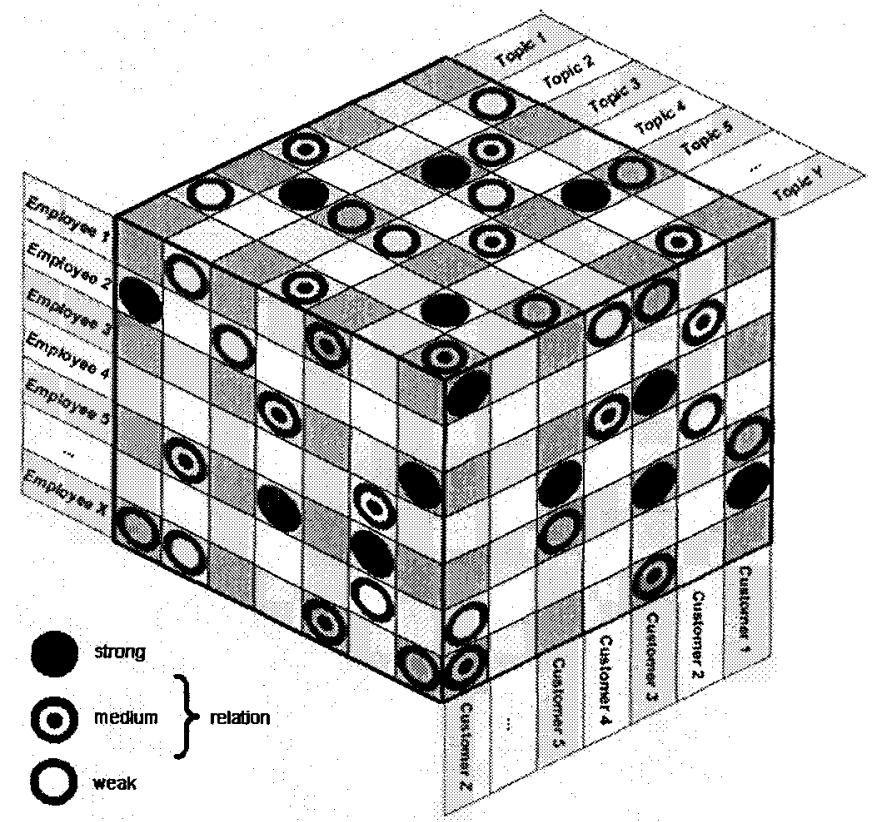

Figure 5. Representation of relation weights by the "Knowledge Cube" (schema)

We call this "Knowledge Cube" because we think that it is more than a mere information matrix: this component allows - in a specific incident or 
problem or event or interaction - to allocate and connect information in three dimensions to each other; it is the connection of diverse information in relation to an event or a specific question which generates knowledge from information; otherwise diverse lists of information could not contribute to knowledge, or the knowledge of employees would remain tacit. This means: the "Knowledge Cube" does not itself represent knowledge, but it can help in generating knowledge in the heads of employees.

Therefore, the cube must be very easy to use in work actions; it must be user-friendly, or it will not be used.

There are many applications of this platform component. Questions which could be posed to the "Knowledge Cube", are for example:

- If employee A retires in the near future. Who is the company to train in his special knowledge areas in order to avoid a gap? Where exactly and with respect to which customers and topics will be the knowledge gaps when the experienced employee leaves?

- Customer B is on the phone and demands to talk to employee $\mathrm{C}$ who is on vacation. Who else in the company knows this customer and his typical orders so that the call can be redirected to him/her?

- A new rapid prototyping technology is introduced in the company; this will be a new core competency or topic. Which customers might be interested in this for future orders? Which employees should be trained to work with that new technology? Which kind of orders and services could as well be performed by the new technology?

Knowledge is needed to give an answer to a question; it has to be generated in order to solve an actual problem. The lists of customers, employees and topics contain simple information; it is their connection and relation in work actions that generates knowledge in the heads of employees. The "Knowledge Cube" itself cannot represent, generate nor contain knowledge it is a tool for managers and engineers to find connections and relationships. Therefore we think that the process of identifying, allocating, connecting and contributing information (maybe in a collective effort, discussion, workshops) is more important and productive for the knowledge of a company than the result: the cube in its specific developmental stage (to stay with the visualisation in Figure 5: with dozens of "dots" and "rings") in a continuous process.

\subsection{The "Generic Knowledge Cube"}

In a second step the above-described "Knowledge Cube" was enhanced by some concepts that made it more flexible and abstract. 
- The semantics of the lists within the "Generic Knowledge Cube" is opened for other entities than just employees, customers and topics to be represented, for example projects or machines;

- Furthermore, the "Generic Knowledge Cube" can contain any number of lists, according to individual needs;

- Finally, it is possible to define weighted relations between elements of the same list; this allows for instance to detect close relationships between different employees, customers, etc.

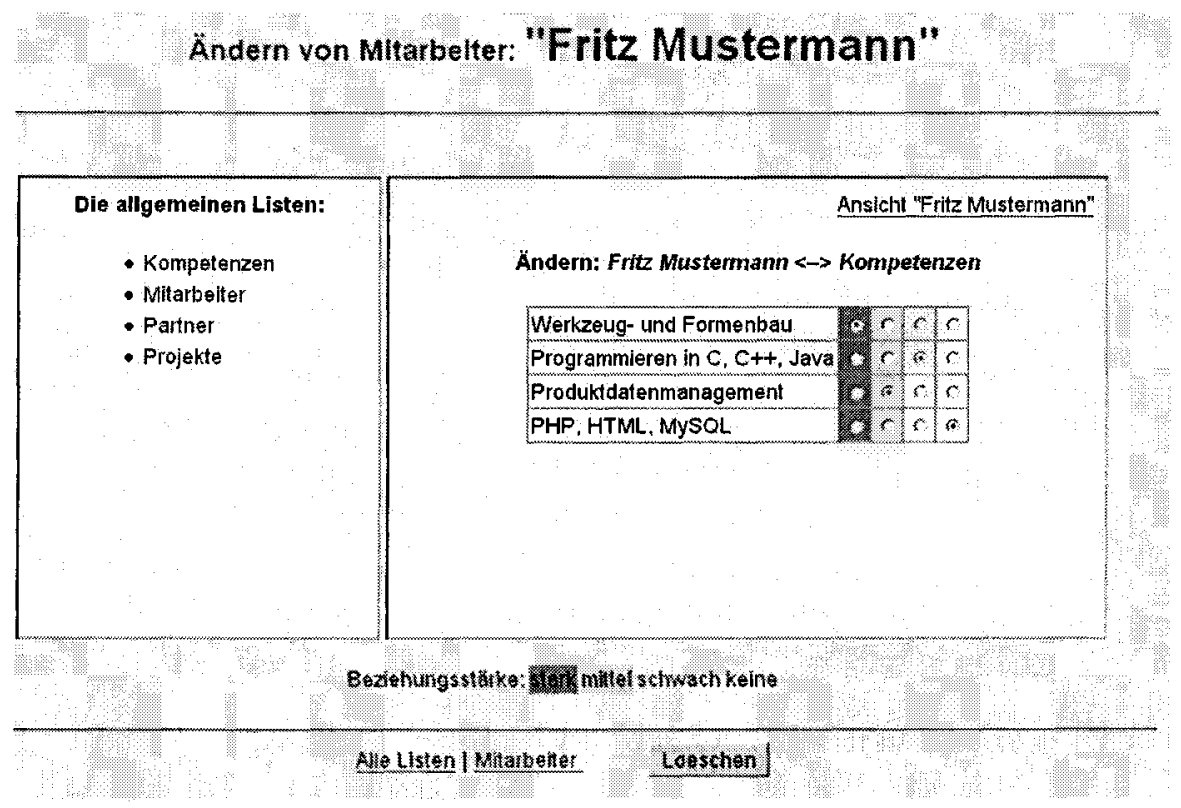

Figure 6. Screenshot of one item in the list of employees (a person) in the "Generic Knowledge Cube"

\subsection{Future prospects and potentials}

In discussions about the "Knowledge Cube", several new ideas were brought up that might be of use when thinking about the incorporation of the "Knowledge Cube" in new and extended contexts:

- to mark relationships between elements of lists with additional information, instead of just stating their weight: this could be comments, protocols, documents, pictures, or any other data; 
- to introduce grouping structures for lists (like folders in file systems) together with appropriate inheritance mechanisms, which will ease the handling of long lists;

- to add timestamp and history functions that trace changes;

- to realise graphical representations of different kinds for the database content: tables, detail views, global views, dynamic graphs, ...

\section{NETWORKING AND COLLABORATING}

The communication platform and the virtual showcase open a wide space for communication and collaboration with customers on the one side and partners/subcontractors on the other. The platform was designed according to the needs and requirements of users in SMEs offering Rapid Prototyping $\&$ Rapid Tooling services. The functionalities of the platform support the diverse tasks and activities of technical advisors interacting with customers and partners.

The agepro project expects that the work processes and characteristics of work activities will develop as soon as the platform will be implemented. However, there will not be a sudden change to networking and collaborating. We expect a slow evolution of new characteristics of work. It takes time for the engineers to realise the potential of the new communication and collaboration space and to develop appropriate activity patterns and communicative behaviour (interacting with clients and partners anywhere and anytime). We hypothesise that within a year or two this change of activity patterns, attitudes and mindsets will have developed. The hypothesis is explicated (with respect to the work of technical advisors for Rapid Prototyping \& Rapid Tooling services) in a comparison or even confrontation of "today" and "tomorrow". We formulated the features in an ideal type and polarised way (Table 1 and 2), thus we make new characteristics visible in the first stages of developments. Our assumptions are based on observations in the book "The rise of the network society" (CASTELLS 2000) as well as empirical work analysis, applying the VERA/RHIA method (LEITNER et al. 1993), interviews and extensive observations in the participating SMEs. The assumptions should be fruitful for analyses and explication.

The evolution of a new style of interaction and communication in networks (networking) implies a new concept for "cooperation/ collaboration". Processes and configurations in networks are different from established hierarchical structures; therefore evolving characteristics of networking necessitates different competencies and appropriate training and qualification. In agepro we found, that in terms of qualification and training no additional 
content, professional competence or knowledge is required for networking but rather a change of attitude, mindsets and communicative behaviour.

Table 1. Characteristics of networking and collaborating

(according to AUMUND-KOPP 2003, p. 191)

\begin{tabular}{|c|c|c|}
\hline & $\begin{array}{l}\text { today : conventional proc- } \\
\text { esses }\end{array}$ & tomorrow: e-business structures \\
\hline \multirow{2}{*}{ 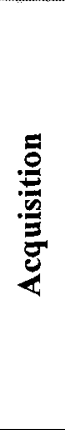 } & $\begin{array}{l}\text { Customers come to service } \\
\text { provider. }\end{array}$ & $\begin{array}{l}\text { Customers are called on and visited; } \\
\text { they are advised specifically to their } \\
\text { requirements; acquisition and } \\
\text { communication with customers on the } \\
\text { long run. Attention is called to } \\
\text { homepage and platform. }\end{array}$ \\
\hline & $\begin{array}{l}\text { Customers ask via mail, fax or } \\
\text { telephone. }\end{array}$ & $\begin{array}{l}\text { Customers interact on homepage, } \\
\text { communication platform, virtual } \\
\text { showcase; e. g. semi-automatic request } \\
\rightarrow \text { answer and generation of offer, } \\
\text { client-specific advice. }\end{array}$ \\
\hline \multirow{4}{*}{$\frac{8}{2}$} & $\begin{array}{l}\text { Consultation of customer in own } \\
\text { office. }\end{array}$ & $\begin{array}{l}\text { Consultation with customer in his } \\
\text { office. }\end{array}$ \\
\hline & $\begin{array}{l}\text { Receive and collect information } \\
\text { at own desktop. }\end{array}$ & $\begin{array}{l}\text { Take up and collect information at } \\
\text { client's office, mobile data entry. }\end{array}$ \\
\hline & $\begin{array}{l}\text { Demonstrations with physical } \\
\text { models. }\end{array}$ & Demonstrations with virtual exhibits. \\
\hline & $\begin{array}{l}\text { Information predominantly on } \\
\text { paper. }\end{array}$ & Information, data predominantly digital. \\
\hline \multirow[t]{2}{*}{$\frac{1}{2}$} & $\begin{array}{l}\text { Company conceives itself as } \\
\text { discrete and singular, behaves } \\
\text { individually in relation to } \\
\text { competitors, partners and } \\
\text { subcontractors. }\end{array}$ & $\begin{array}{l}\text { Company distinguishes itself and takes } \\
\text { position with its core competencies in a } \\
\text { network of cooperating partners. }\end{array}$ \\
\hline & $\begin{array}{l}\text { Few stable and long lasting } \\
\text { relations. }\end{array}$ & Many weak and short range relations. \\
\hline \multirow{3}{*}{ 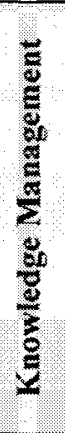 } & $\begin{array}{l}\text { Experience and tacit knowledge } \\
\text { is in the heads of employees - } \\
\text { distributed all over the } \\
\text { company's processes, cannot } \\
\text { easily be found and combined. }\end{array}$ & $\begin{array}{l}\text { Information about customers, orders and } \\
\text { processes are documented; they are } \\
\text { available anytime and can be networked } \\
\text { and processed to knowledge. }\end{array}$ \\
\hline & $\begin{array}{l}\text { Info exchange and connection } \\
\text { often happen by chance, are } \\
\text { undirected. }\end{array}$ & $\begin{array}{l}\text { Access to all kinds of information is } \\
\text { direct and precise. }\end{array}$ \\
\hline & $\begin{array}{l}\text { Communication between a } \\
\text { person and a specific other } \\
\text { person. }\end{array}$ & $\begin{array}{l}\text { Single person communicates with a } \\
\text { group, e.g. online communities. }\end{array}$ \\
\hline
\end{tabular}


Special topics, arising from the transformation to e-business structures in Rapid Prototyping \& Rapid Tooling services, should be incorporated into qualification activities and training:

- go out for mobile work, find new customers, identify their needs

- help customers to identify implicit problems and present solutions

- be pro-active and take initiative in communication with the environment of the company

- contribute to and share information with network - instead of protect and hedge

- expose your company's competencies and search for opportunities in the web

- demonstrate Rapid Prototyping/Rapid Tooling expertise with masterpieces in "virtual showcase"

- communicate with several partners at the same time in networks

- think beyond company walls, see partners instead of competitors

- empower technical advisors for self-dependent, mobile interaction

- identify and manage in-house knowledge about customers and previous orders

- make use of the company's core competencies, the employees' experience and know-how, and the lessons learned (mistakes) in Rapid Prototyping processes and on shop floor

- make use of methods to filtrate relevant information out of masses of data

All these are imperative formulations, directed to those, who want to start networking successfully. SME managers should lead their employees into networks and show the options of networking, thus they will accelerate the evolution of a new way of working.

\section{ACKNOWLEDGEMENTS}

The research and development project agepro was funded by the German Federal Ministry of Research and Technology (BMBF) in the framework programme "Innovative Arbeitsgestaltung - Zukunft der Arbeit" (project no: 01HT0131-135). 


\section{REFERENCES}

AUMUND-KOPP, Claus; ELLEBRECHT, Frank; FRICKE, Holger; GOTTSCHALCH, Holm; PANSE, Christian:

Networking and Collaborating on a Platform in Design and Production of Models and Tools.

In: Human Aspects in Production Management.

Eds.: ZÜLCH, Gert; STOWASSER, Sascha; JAGDEV, Harinder S.

Aachen: Shaker Verlag, 2003, pp. 187-193.

(esim - European Series in Industrial Management, Volume 5)

CASTELLS, Manuel:

Der Aufstieg der Netzwerkgesellschaft.

Opladen : Leske + Budrich, 2001.

LEITNER, Konrad; LÜDERS, Elke; GREINER, Birgit: DUCKI, Antje; NIEDERMEIER, Renate; VOLPERT, Walter:

Analyse psychischer Anforderungen und Belastungen in der Büroarbeit - Das

RHIA/VERA-Büro-Verfahren Handbuch.

Göttingen: Hogrefe Verlag für Psychologie, 1993. 